\title{
Application of primary cell cultures of laryngeal carcinoma and laser scanning cytometry in the evaluation of tumor reactivity to cisplatinum
}

\author{
Janusz Klatka ${ }^{1}$, Roman Paduch ${ }^{2}$, Piotr Pożarowski ${ }^{3}$, Wioletta Pietruszewska ${ }^{4}$, \\ Krzysztof Kupisz ${ }^{5}$, Piotr Trojanowski ${ }^{1}$, Jacek Roliński ${ }^{3}$ \\ ${ }^{1}$ Department of Otolaryngology and Laryngeal Oncology, Medical University in Lublin, Poland \\ ${ }^{2}$ Department of Virology and Immunology. Institute of Microbiology and Biotechnology, \\ Maria Curie-Skłodowska University in Lublin, Poland \\ ${ }^{3}$ Department of Clinical Immunology, Medical University in Lublin, Poland \\ ${ }^{4}$ Department of Otolaryngology, Medical University of Lodz, Poland \\ ${ }^{5}$ Department of Otolaryngology, District Hospital in Lublin, Poland
}

\begin{abstract}
Unsatisfactory effects of treatment of laryngeal carcinoma patients stimulate the clinicians as well as researchers to develop new more effective treatment models and to find new reliable prognostic factors. The aim of the present study was the evaluation of the use of primary cell cultures of the laryngeal carcinoma and laser scanning cytometry (LSC) in the assessment of tumor reactivity to cisplatinum. Nineteen primary cultures of laryngeal carcinoma cells established from fragments of laryngeal carcinoma infiltrations were cultured with or without cisplatin, stained with monoclonal antibodies against P53 and BCL-2 proteins and analyzed by LSC. Cisplatin added to the culture medium leads to the significant increase of P53 expression and decrease of BCL-2 expression. Moreover, changes of P53 and BCL-2 expressions were significantly correlated. Our findings of apoptosis regulatory mechanisms could be useful in patient qualification for the chemotherapeutic follow-up treatment.
\end{abstract}

Key words: Primary cell culture - Laser scanning cytometry - P53 - BCL-2

\section{Introduction}

The increasing morbidity and unsatisfactory effects of treatment, especially in cases of advanced laryngeal carcinoma, stimulate the researchers to develop new more effective chemotherapy schemes within the radical combined treatment.

The role of chemotherapy as a part of the radical treatment for advanced head and neck cancer is still controversial [1]. Optimal drug combination and sequence of chemotherapy to other methods are unknown. It seems that creating a model that may be used to evaluate the reactivity of laryngeal carcinoma

Correspondence: J. Klatka, Department of Otolaryngology and Laryngeal Oncology, Medical University in Lublin, Szerokie Str. 7B, 20-050 Lublin, Poland; tel.: tel. (+4881) 7244751, fax. (+4881) 7244517, e-mail: janusz.klatka@wp.pl cells to the cytostatic planned in therapy in vitro may help to choose a suitable cytostatic and contribute to the improvement of therapeutic effects in this type of cancer.

Almost 35 years ago, Kerr et al. suggested that apoptosis would be pronounced in tumors subjected to the action of selected agents such as irradiation or cytostatic drugs [2]. At present apoptosis is known to be induced in tumor cells by multiple cytostatic drugs of a variable chemical structure and different mechanisms of action. The product of P53 tumor suppressor gene has been implicated as a critical factor in the regulation of this process mediated by DNA damaging agents, because of its involvement in the control of genetic stability [3]. The first proto-oncogene shown to be involved in the regulation of apoptosis was BCL2 [4]. The BCL-2 protein can inhibit apoptosis triggered by different cytotoxic agents. 
Cisplatin (cis-diamminedichloroplatinum; CDDP) is one of the most potent and useful antitumor agents for the treatment of malignant solid tumors. The activated compound reacts with cellular DNA to form interstrand and intrastrand crosslinks. Itrastrand crosslinks inhibit DNA replication and RNA transcription, leading to DNA breaks and miscoding that are either mutagenic or lethal for the affected cell [5].

The aim of the study was the evaluation of the use of primary cell cultures of the laryngeal carcinoma and laser scanning cytometry in the presentation of tumor reactivity to cisplatinum. Changes in the expression of P53 and Bcl-2 protein were assumed as reactivity indicator.

\section{Material and methods}

Sample material. Primary cultures of laryngeal carcinoma cells were established from fragments of laryngeal carcinoma infiltrations, collected from 19 patients immediately after laryngectomy. The method of growing the cultures of laryngeal carcinoma cells is presented in details in our earlier study [6].

The method of growing the cultures of laryngeal carcinoma cells. The material intended for the cell culture establishment was collected aseptically from laryngeal carcinoma infiltration, directly after laryngectomy. The fragment of the cancer tissue was transferred onto sterile Petri dish and cleared from clotted blood and visible necrotic tissue.

After 5 min. washing in culture medium (MEM) (Gibco BRL), the tissue was divided into several parts which were placed in antibiotic solution $(300 \mathrm{U} / \mathrm{ml}$ penicillin, $300 \mu \mathrm{g} / \mathrm{ml}$ streptomycin, $0.75 \mu \mathrm{g} / \mathrm{ml}$ amphotericin B, $25 \mu \mathrm{g} / \mathrm{ml}$ tylosin, $300 \mu \mathrm{g} / \mathrm{ml}$ kanamycin) (Sigma). After 1 hour of incubation at room temperature the fragments were washed in culture medium without antibiotics and transferred onto new sterile Petri dish. The material was then crumbled with scissors and culture medium supplemented with $10 \%$ fetal bovine serum (FBS) and antibiotics $(100 \mathrm{U} / \mathrm{ml}$ penicillin, $100 \mu \mathrm{g} / \mathrm{ml}$ streptomycin and $0.25 \mu \mathrm{g} / \mathrm{ml}$ amphotericin B) was added to the small tissue parts $\left(<0.1 \mathrm{~mm}^{3}\right)$.The tissue suspension was transferred into wells of the Lab-Tek chamber slide (8-well) (Nunc.) and cultured at $37^{\circ} \mathrm{C}$ with $5 \% \mathrm{CO}_{2}$ incubator for 2-4 weeks.

The expression and BCL-2 and P53 protein was estimated in tumor cell outgrowths from single tissue fragments adhered to the bottom surface of the well.

Immunohistochemistry. Before the basic immunocytochemical determination of P53 and BCL-2 was performed, the presence of squamous epithelium carcinoma cells was confirmed in each culture by carrying out the immunocytochemical test with a monoclonal antibody - cytokeratin (clon MNF116) produced by DAKO directed toward keratin filaments.

In the first stage of carrying out the immunocytochemical reaction the cell cultures were washed twice with PBS and fixed for 15 min. in $0.25 \%$ paraformaldehyde in the dark at room temperature. After the next washing with PBS, glass slides with cultures were immersed in $75 \%$ methanol for 24 hours at $+4^{\circ} \mathrm{C}$. Cultures were rehydrated and incubated with mice monoclonal antibodies directed toward human P53 (Do-7; Dako, Glostrup, Denmark), working concentration 1:25, and Bcl-2 (124, Dako), working concentration 1:20; at room temperature for 1 hour. After washing with PBS cultures were incubated for 1 hour with anti-mice secondary antibody conjugated with FITC. Cell cultures were washed again with PBS
Table 1. The expression of P53 and BCL-2 protein in laryngeal carcinoma cell cultures with and without cisplatinum treatment.

\begin{tabular}{|c|c|c|c|c|}
\hline Culture nr & P53(K) & P53 (CIS) & BCL2(K) & BCL2 (CIS) \\
\hline 1 & 381153 & 5481026 & - & - \\
\hline 2 & 423685 & 529500 & - & - \\
\hline 3 & 213682 & 262111 & - & - \\
\hline 4 & 379931 & 313283 & - & - \\
\hline 5 & 198446 & 279456 & 113252 & 107347 \\
\hline 6 & 66156 & 150940 & 324896 & 168536 \\
\hline 7 & 340271 & 1218188 & 1411180 & 661064 \\
\hline 8 & 289276 & 336862 & 151850 & 596379 \\
\hline 9 & 1124883 & 1240325 & 1290418 & 1261392 \\
\hline 10 & 111865 & 487301 & - & - \\
\hline 11 & 1159461 & 566698 & 577997 & 1457788 \\
\hline 12 & 576147 & 739233 & - & - \\
\hline 13 & 523910 & 1006506 & 120526 & 328787 \\
\hline 14 & 390583 & 68283 & 501298 & 1445771 \\
\hline 15 & 304902 & 544218 & 428728 & 267659 \\
\hline 16 & 1428155 & 1274249 & 467145 & 881127 \\
\hline 17 & 3675436 & 3942343 & 4054474 & 2228560 \\
\hline 18 & 177421 & 338053 & 323124 & 685982 \\
\hline 19 & - & - & 2974633 & 1477232 \\
\hline
\end{tabular}

and, in order to stain DNA, propidine iodide $(5 \mu \mathrm{g} / \mathrm{ml})$ was added in the presence of RNAse $(100 \mu \mathrm{g} / \mathrm{ml})$ and slides were incubated for $30 \mathrm{~min}$. at room temperature. After the last washing specimens were mounted with glycerol and covered with a cover glass.

Methods of measurement of P53 and BCL-2 expression in primary cultures of laryngeal carcinoma. The measurement of P53 and BCL-2 expression was performed using a laser scanning cytometre CompuCyte LSC (CompuCyte Inc., Cambridge, Massachusetts). Specimens were evaluated in LSC immediately after their preparation. Fluorescence was induced using argon laser light of $488 \mathrm{~nm}$ wave length. PI and FITC fluorescence were exited by 488-nm laser and measured by separate photomultipliers using standard dichroic mirrors and emission filters. Entire slides were scanned. Threshold contour was set on PI fluorescence enabling to separate nuclear fluorescence. Total green fluorescence was measured within the integration contour (which was enlarged to cover all specific fluorescence). Cisplatinum treated and untreated cell cultures were located in the same slides and were subjects of the same staining procedures. All details of the method were described in our previous study $[13,14]$.

Statistical analysis. The statistical analysis of the collected material was carried out using STATISTICA 6.0. programme. The change in the expression of studied proteins after the incubation of the primary cell cultures with cisplatinum was evaluated using the Wilcoxon significance test. The evaluation of dependence between the changes in the expression of P53 protein and changes in the 


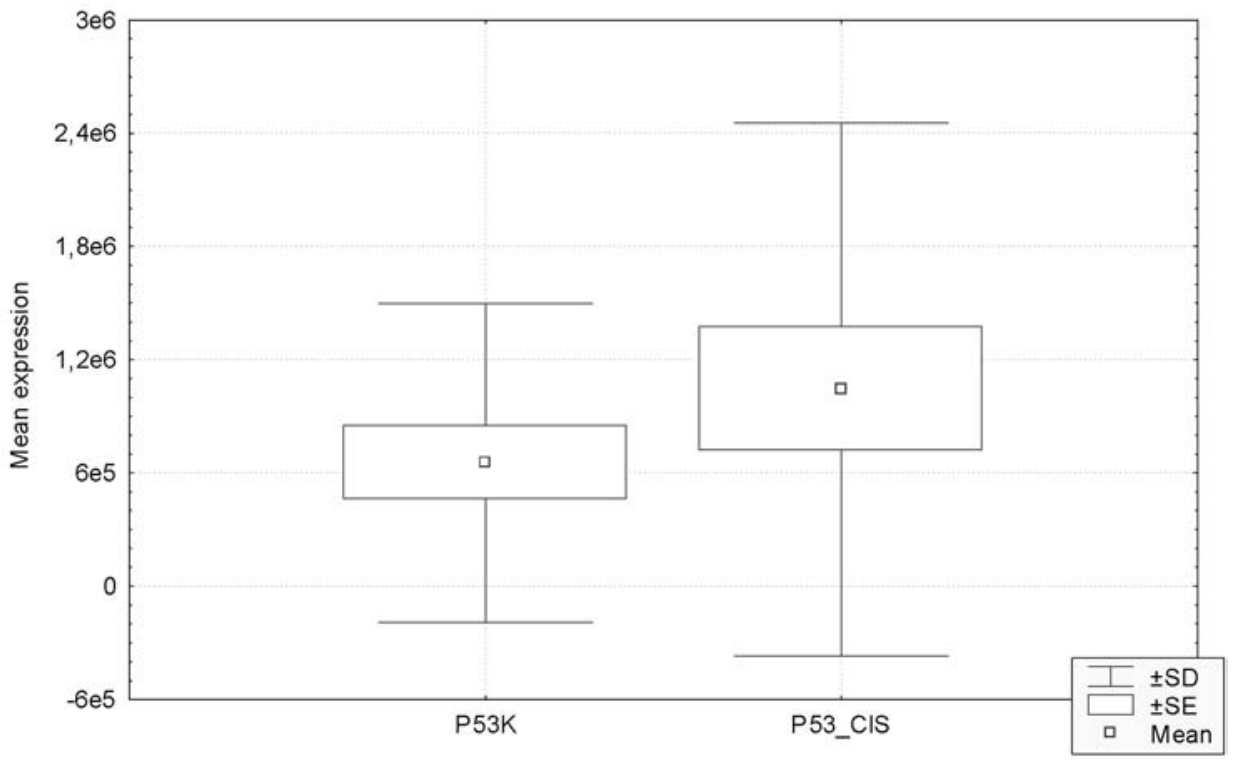

Fig. 1. Expression of P53 protein in primary cell cultures of laryngeal carcinoma before and after the incubation with cisplatinum in the dose of $0.5 \mu \mathrm{g} / \mathrm{ml}$. expression of BCL-2 protein in the primary cultures after the incubation with cisplatinum was carried out using the accurate Fisher test and the Spearman test for the correlation coefficient .

\section{Results}

A total of 35 specimens were obtained for evaluation, and 19 of them $(54 \%)$ were grown in vitro.

Statistically significant increase in the expression of $\mathrm{P} 53$ protein in studied cultures, after the incubation with cisplatinum in the dose of $0.5 \mu \mathrm{g} / \mathrm{ml}$, was confirmed by the analysis of results using par Wilcoxon sequence test $(T=40.00, p<0.05)$, which is presented in Fig.1. The increase in the expression of P53 protein was observed in 14 out of 18 primary cultures of laryngeal carcinoma after the incubation with cisplatinum. In the remaining 4 cultures the decrease in the expression of P53 was observed (Table 1).

The decrease in the expression BCL-2 protein was found in 6 out of 13 cultures and the increase in BCL2 in the remaining 7 cultures (Table 1).

The increase in the expression of $\mathrm{P} 53$ protein was accompanied by the decrease in the level of Bcl-2 protein in cell cultures of laryngeal carcinoma after the incubation with cis-platinum. In 9 cultures, where the expression of P53 protein in the cells increased after administering cytostatic, the increase in the level of cell protein BCL-2 was found in 3 cultures $(33.3 \%)$ and the decrease in 6 cultures $(66.6 \%)$. The Spearman test for the correlation coefficient confirmed a significant correlation between changes in the expression of P53 protein and changes in the expression of BCL-2 protein after the incubation with cis-platinum $(\mathrm{r}=-$ $0.7972, \mathrm{p}<0.005)$ (Fig.2). It was also confirmed by the accurate Fisher test $(\mathrm{p}<0.05)$.

\section{Discussion}

Experiments performed on primary cell cultures in vitro are currently one of the most popular and effective methods to test the expression of selective markers on tumor cells or analyze cell sensitivity to new substances or clinically used cytostatics. The results could be useful in choosing the kind and dose of drugs that might be administered to the patient [8]. However, such analysis should be applied only as preliminary studies and should be considered as screening tests. However, many oncologists begun to accept the results of immunocytochemical staining of primary cell cultures as an additional and helpful method beside immunohistochemical paraffin-embedded tissue section analysis, which may be used in modern pathology. Moreover, the advantage of primary tumor cell culture is the unchanged membrane and cytoplasmic marker expression that closely reflects the origin of tissue. Therefore, the results of e.g. P53, BCL-2 and syndecan-1 expression on primary tumor cells in vitro enable to foresee potential resistance or sensitivity of, e.g. laryneal carcinoma cells to planned chemotherapy.

There are several techniques for the culture of cancer cells $[6,9,10]$. This study presents that laryngeal cancer may grow in a liquid overlay system. Squamous cell carcinoma of larynx was successfully cultured from 21 of 39 specimens (54\%). The vast majority of specimens that did not grow were taken directly from primary tumors of the larynx. This is not surprising because the tumors are frequently necrotic and grossly infected. Gębarowski et al. reported that they developed 45 cultures from 65 solid tumors $(70 \%)$ but Mattox et al. successfully cultured 33 from 75 specimens $(45 \%)[8,10]$. 


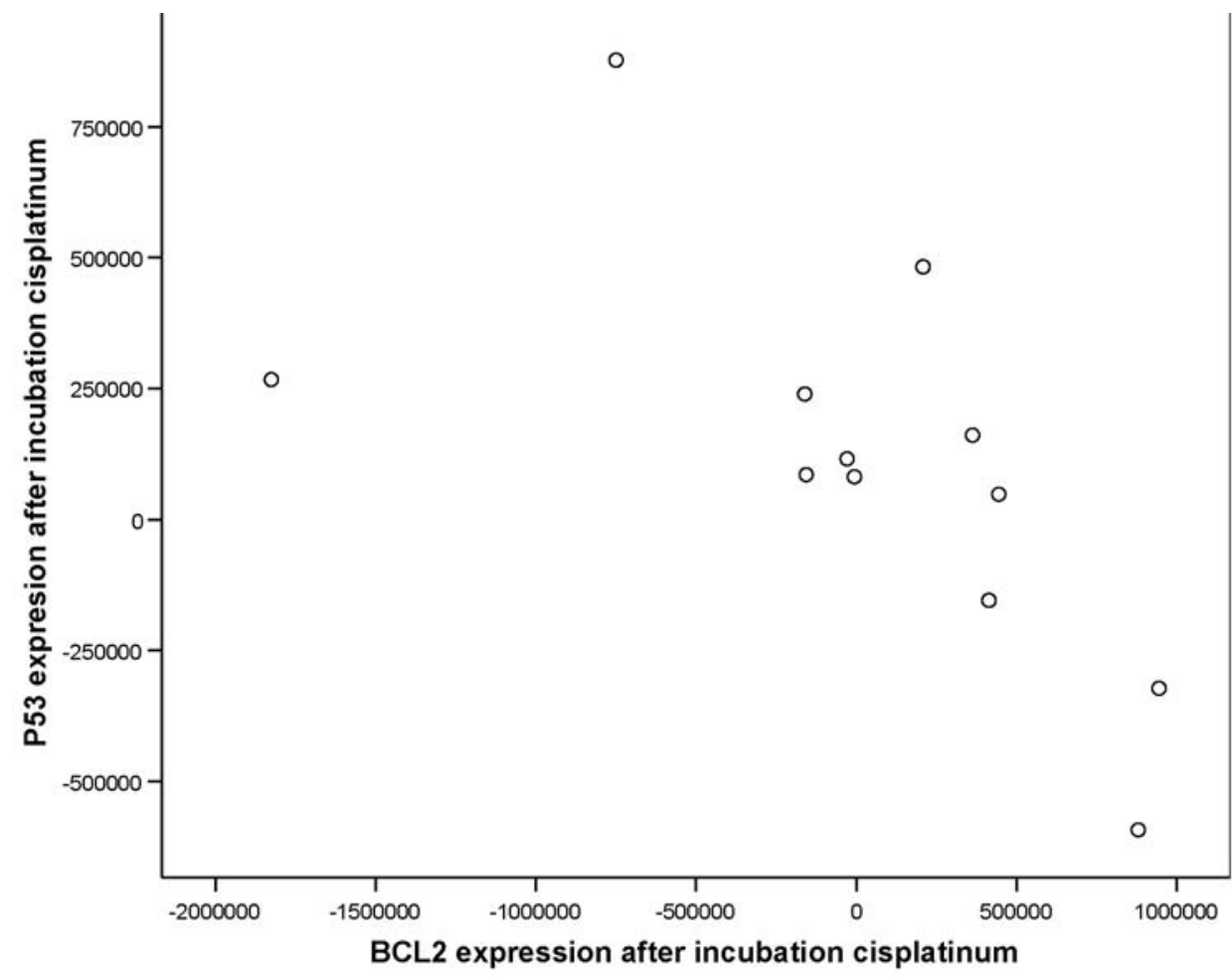

Fig. 2. Correlation between the change in the expression of P53 protein and the change in the expression of BCL-2 protein in primary cell culture of laryngeal carcinoma after the incubation with cisplatinum $(r=-0.7972, p<0.005)$.
It should be emphasized, that adaptation of LSC in the present study to measure individual colonies enables to measure the expression of P53 and BCL-2 of the clone in situ, without detaching and dispersing the cells which is required for example when the measurement is taken by the flow or image cytometry. The cultures were set up using commercially available chambers based on microscope slides. This enabled us to fix and stain the colonies on the same slides, which were then directly subjected to fluorescence measurements by LSC. The cells were then intact, not enzymatically injured and expressing proteins similarly to the original tissue.

Our study reveals that the expression of P53 is increased in 14 of 18 laryngeal carcinoma cell cultures after the incubation with cisplatinum $(0.5 \mu \mathrm{g} / \mathrm{ml})$. The BCL-2 changes, however, were variable after the incubation with cisplatinum, the increased expression of BCL-2 was observed in 6 and the decreased expression of BCL-2 was expressed in 7 cultures. There were also interdependencies between the increased P53 and decreased expression of BCL-2 in 5 primary laryngeal carcinoma cell cultures after cisplatinum administration.

Recent studies have demonstrated that at least two pathways regulate apoptosis: one dependent on the tumor suppressor gene P53 and the other P53-independent $[11,12]$.

Cisplatinum has been reported to activate P53, as a response to the formation of DNA inter- and intra- stand cross-links [15]. Many studies have described cell cycle effects induced by cisplatinum, the inhibited progression through $\mathrm{S}$ phase and the block in G2M being the principal perturbations [16]. After long treatment with high concentrations of the drug, an additional block in G1 was detected together with the cell death distributed in all cell cycle phases [17]. G1 arrest induced by cisplatinum has been reported to be P53independent [18].

The effects of cisplatinum on cell apoptosis have been investigated in a number of human cancer cell lines.

Ikeguchi et al. reported the increase of expression of P53 protein in one of four investigated gastric cancer cell lines after the incubation with cisplatinum and decrease in BCL-2 protein expression in other investigated cancer cell lines. After the incubation with cisplatinum, apoptotic cells were detected more frequently among cells with a wild-type gene for P53 and without expression of the BCL-2 protein than among cells with a mutant or complete deletion of the gene for p53 and with overexpression of BCL-2 protein [19].

Yip HT et al. observed in two of three investigated carcinoma cell lines of head and neck cancers the increased expression of p53, p21, p16, BCLxL, and BCLxS genes with cisplatinum treatment. Expression of p27, DP1, MDM2, BCL-2, c-iun and jun-D remained unaltered after treatment [20].

P53 status or BCL-2 expression have been implicated as useful predictors of chemosensitivity of ovar- 
ian carcinoma [21] or resistance [22]. In vitro, p53 mutations were associated with down-regulation of Bax, a protein promoting apoptosis in the IGROV-1/Pt cells [21].

The human tumor culture assay has proved to be an important adjunct in the management of ovarian carcinoma, myeloma, and melanoma. In a group of heavily pretreated patients, this system correctly predicted sensitivity to cancericidal drugs with $62 \%$ accuracy and resistance with 96\% accuracy [23]. Therefore, although in vitro sensitivity does not guarantee the same results in patients, generally in vivo resistance is a strong argument for the selection of another chemotherapeutic agent.

On the other hand Burger et al. and Perego et al. suggested that at least in their panel of tumor cell lines, hypersensitivity or resistance to cisplatin might not be necessarily correlated with the presence of wild-type of P53 and probably not associated with BCL-2 and Bax expression [7,24].

Our results obtained in primary cultures of laryngeal carcinoma cells with the use of laser scanning cytometry reveal that in this way it is possible to determine very precisely the tendency and the extend of changes in the expression of P53 and BCL-2 in these carcinoma cells after the incubation with cisplatinum. The correlation between the expression of P53 and Bcl-2 protein, found in a certain number of studied cultures, indicates that in these cultures P53 dependent apoptosis is induced after the incubation with cisplatinum. It seems that the model for the evaluation of the expression of P53 and BCL-2 protein in primary cells of laryngeal carcinoma using laser scanning is helpful for the evaluation of reactivity of laryngeal carcinoma to a cytostatic administered in vitro.

\section{References}

[1] Cmelak AJ, Li S, Goldwasser MA, Murphy B, Cannon M, Pinto H, Rosenthal DI, Gillison M, Forastiere AA. Phase II trial of chemoradiation for organ preservation in resectable stage III or IV squamous cell carcinomas of the larynx or oropharynx: results of Eastern Cooperative Oncology Group Study E2399. J Clin Oncol. 2007;25:3971-7.

[ 2] Kerr JF, Wyllie AH, Currie AR. Apoptosis: A basic biological phenomenon with wider ranging implications in tissue kinetics. Br J Cancer. 1972;24:239-275.

[ 3] Wilkins DE, Ng CE, Raaphorst GP. Cell cycle disturbances and mitotic catastrophes in HeLa Hep2 cells following 2.5 to $10 \mathrm{~Gy}$ of ionizing radiation. Clin Cancer Res. 2007;13:5501-5508.

[ 4] Fernandez-Luna JL. Apoptosis regulators as targets for cancer therapy. Clin Transal Oncol. 2007;9:555-62.

[5] Rosenberg B, Camp L van, Trosko JE, Mansour VH. Platinum compounds: a new class of potent antitumor agents. Nature. 1996;222:385-386.

[ 6] Rzeski W, Paduch R, Klatka J, Kandefer-Szerszeń M, Stepulak A, Pożarowski P, Zdzisińska B. Establishment and preliminary characterization of the two cell lines derived from larynx carcinoma. Folia Histochem Cytobiol. 2002;40:195-196.
[ 7] Perego P, Righetti SC, Supino R, Delia D, Caserini C, Carenini N, Bedogne B, Broome E, Krajewsi S, Reed JC, Zunino F. Role of apoptosis and apoptosis-related proteins in the cisplatin-resistant phenotype of human tumor cell lines. Apoptosis. 1997;2:540-548.

[ 8] Gębarowska E., Zabel M., Majewski A., Kołodziej J. Evaluation of individual sensitivity to cytostatic drugs of in vitro cultured lung tumor cells. Folia Histochem Cytobiol. 1999;37, 135-136.

[ 9] Gronau S, Thess B, Riechelmann H, Fischer Y, Schmitt A, Schmitt M. An autologous system for culturing head and neck squamous cell carcinomas for the assessment of cellular therapies on the chorioallantois membrane. Eur Arch Otorhinolaryngol. 2006;263:308-312.

[10] Mattox DE, Van Hoff DD. In vitro stem cell assay in had and neck squamous carcinoma. Am J Surg. 1980;140,527-30.

[11] Bragado P, Armesilla A, Silva A, Porras A. Apoptosis by cisplatin requires 553 mediated p38 $\alpha$ MAPK activation through ROS generation. Apoptosis. 2007;12:1733-1742.

[12] Lupi M, Matera G, Natoli C, Colombo V, Ubezio P. The Contribution of p53 in dynamics of cell cycle response to DNA damage interpreted by a mathematical model. Cell Cycle. 2007;6:943-950.

[13] Pożarowski P, Holden E, Darzynkiewicz Z. Laser Scanning Cytometry (LSC) Principles and Aplications. In: Methods in Molecular Biology. Cell Imaging Techniques. Methods and Protocols. eds. Douglas J. Taatjes and Brooke T. Mossman Humana Press, Totowa, New Jersey, USA, 2005.

[14] Pożarowski P, Huang X, Gong RW, Priebe W, Darzynkiewicz Z. Simple, semi-automatic assay of cytostatic and cytotoxic effects $f$ antitumor drugs by laser-scanning cytometry (LSC): Effects of the bis-intercalator WP631 on growth and cell cycle of T-24 cells. Cytometry. 2004;57A:113-119.

[15] Zamble DB, Jacks T, Lippard SJ. p53- Dependent and independent response to cisplatin in mouse testicular teratocarcinoma cells. Proc Natal Acad Sci USA. 1998;82:74955.

[16] Sorenson CM, Barry MA, Eastman A. Analysis of events associated with cell cycle arrest at G2 phase and cell death induced by cisplatin. J Natl Cancer Inst. 1990;82:749-55.

[17] Bergerat JP, Barlogie B, Gohde W, Johnston DA, Drewinko B. In vitro cytokinetic response of human colon cancer cells to cis-dichlorodiammineplatinum(II). Cancer Res. 1979;39: 4356-63.

[18] Attardi LD, de Vries A, Jasks T. Activation of the p53dependent $\mathrm{G} 1$ checkpoint response in mouse embryo fibroblasts on the specific DNA damage inducer. Oncogene. 2004; 23:973-80.

[19] Ikeguchi M, tatebe S, Kaibara N, Ito H. Canges in levels of expression of p53 and product of the bcl-2 in lines of gastric cancer cells during cisplatin-induced apoptosis. Eur Surg Res. 1997;29:396-402.

[20] Yip HT, Choper R, Chakrabarti R, Veena MS, Ramamurthy B, Srivatson ES, Wang MB. Cisplatin-induced growth arrest of head and neck cancer cells correlates with increased expression of p16 and p53. Arch Otolaryngol Head Neck Surg. 2006;132:317-26.

[21] Perego P, Giarola M, Righetti SC, Supino R, Caserini C, Delia D, Pierotti MA, Miashita T, Ree JC, Ziunino F. Association between cisplatin resistance and mutation of $\mathrm{p} 53$ and reduced bax expression in ovarian carcinoma cell systems. Cancer Res. 1996;56: 556-562.

[22] Silvestrini R, Veneroni S, Daidone MG, Benini E, Boracchi P, Mezzetti M, Di Fronzo G, Rilke F, Veronesi U. The Bcl-2 protein: a prognostic indicator strongly related to $\mathrm{p} 53$ protein in lymph node-negative breast cancer patients. JNCI. 1994;86:499-504. 
[23] Salmon SE, Alberts DE, Durie BG, Meyskens FL, Jones SE, Soehnlen B, Chen HS, Moon T. Clinical correlations of drug sensitivity in the human tumor stem cell assay. Recent Results Cancer Res. 1980;74:300-5.
[24] Burger H, Nooter K, Boersma AWM, Kortland CJ, Stoter G. Expression of p53, Bcl-2 and Bax in sisplatin-induced apoptosis in testicular germ cell tumour cell lines. $\mathrm{Br} J$ Cancer. 1998; $77: 1562-1567$.

Submitted: 28 September, 2007 Accepted after reviews: 15 February, 2008 